\title{
A Validated New Gradient Stability-Indicating LC Method for the Analysis of Doripenem in Bulk and Injection Formulation
}

\author{
Singaram Kathirvel ${ }^{1}$ and Garikapati Devalarao ${ }^{2}$ \\ ${ }^{1}$ Department of Pharmaceutical Analysis, Hindu College of Pharmacy, Amaravathi Road, Guntur 522 002, India \\ ${ }^{2}$ Department of Pharmaceutical Analysis, K.V.S.R Siddhartha College of Pharmaceutical Sciences, Vijayawada 520 101, India \\ Correspondence should be addressed to Garikapati Devalarao; devalarao2007@gmail.com
}

Received 12 February 2013; Revised 18 March 2013; Accepted 19 March 2013

Academic Editor: Antonio Martín-Esteban

Copyright (c) 2013 S. Kathirvel and G. Devalarao. This is an open access article distributed under the Creative Commons Attribution License, which permits unrestricted use, distribution, and reproduction in any medium, provided the original work is properly cited.

\begin{abstract}
A sensitive, precise, specific, linear, and stability-indicating gradient HPLC method was developed for the estimation of doripenem in active pharmaceutical ingredient (API) and in injectable preparations. Chromatographic separation was achieved on $\mathrm{C}_{18}$ stationary phase with a mobile phase gradient consisting of acetonitrile, methanol, and $\mathrm{pH} 5.2$ phosphate buffer. The mobile phase flow rate was $0.8 \mathrm{~mL} / \mathrm{min}$, and the eluted compounds were monitored at $210 \mathrm{~nm}$. The method is linear over the range of 0.335 to $76.129 \mu \mathrm{g} / \mathrm{mL}$. The correlation coefficient was found to be 0.999 . The numbers of theoretical plates and tailing factor for doripenem were 53021 and 0.9, respectively. Doripenem was subjected to the International Conference on Harmonization $(\mathrm{ICH})$ prescribed hydrolytic (acid, base, and neutral), oxidative, photolytic, and thermal stress conditions. Among all the abovementioned conditions, the drug was found to be stable under photolytic degradation. Peak homogeneity data for doripenem in the chromatograms from the stressed samples obtained by use of the photodiode array detector demonstrated the specificity of the method for analysis of doripenem in presence of the degradation products. The performance of the method was validated according to the present ICH guidelines for specificity, limit of detection, limit of quantification, linearity, accuracy, precision, and robustness.
\end{abstract}

\section{Introduction}

Doripenem (S-4661) (Figure 1) is a recently developed member of the carbapenem class of beta-lactam antibiotics. Similarly to meropenem and ertapenem, but unlike imipenem, doripenem has a $1-\beta$-methyl side chain that provides resistance to the renal enzyme I-dehydropeptidase. Doripenem has been shown to have broad-spectrum activity against Gram-negative and Gram-positive pathogens including strains of Pseudomonas aeruginosa [1, 2]. Doripenem, like other carbapenems, was developed for the treatment of hospitalized patients with moderate or severe bacterial infections [3].

An extensive literature survey revealed that there are certain methods reported on the stability of doripenem both in solid state and solutions [4-13]. In our knowledge and after an exhaustive revision of the literature, there is no evidence about the stability indicating gradient HPLC assay method of this drug in bulk and its formulation. Moreover, an official method for its determination has not been yet described in any Pharmacopoeia. Consequently, the implementation of an analytical methodology to determine doripenem in API and its formulation is a pending challenge of the pharmaceutical analysis. The objectives of the research work reported in this paper were to develop a suitable gradient stability-indicating LC method for analysis of doripenem in bulk and its injection formulation and to validate the method for specificity, LOD, LOQ, linearity, precision, accuracy, and robustness to show the stability-indicating power of the method and to ensure compliance with ICH guidelines $[14,15]$.

\section{Experimental}

2.1. Materials and Reagents. Active pharmaceutical ingredient standard and samples were supplied by Ortho-McNeil Pharmaceuticals, Raritan, NJ, USA. Doribax (doripenem for injection $250 \mathrm{mg} / \mathrm{vial}$ and $500 \mathrm{mg} / \mathrm{vial}$ ) was used for the present study. Methanol, HPLC-grade acetonitrile, analytical grade potassium phosphate, and potassium hydroxide were 


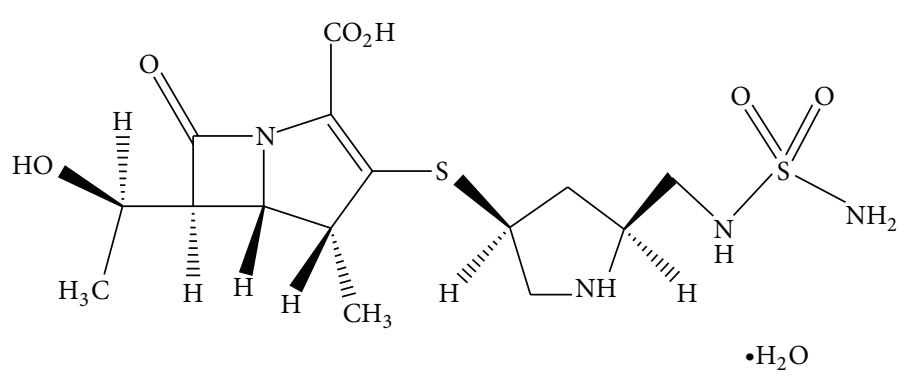

FIGURE 1: Structure of doripenem.

purchased from Merck, Darmstadt, Germany. HPLC-grade water was prepared by using a Millipore Milli-Q Plus water purification system (Millipore Corporate Headquarters, Billerica, MA, USA).

\subsection{Chromatographic Conditions and Equipment. LC was} performed with a Waters system comprising a 2,695 binary pump, an autosampler, and a 2,996 photodiode array (PDA) detector. The output signal was monitored and processed using Empower software on Pentium computer (Digital Equipment). The chromatographic column used was Hypersil BDS C18, $150 \times 4.6 \mathrm{~mm}, 5 \mu \mathrm{m}$ particles. Separation was achieved using a gradient method. Mobile phase A contained a mixture of $\mathrm{pH} 5.2$ phosphate buffer, acetonitrile, and methanol in the ratio of 1000:5:5 (v/v/v), respectively. Phosphate buffer ( $\mathrm{pH}$ 5.2) was prepared by weighing and dissolving accurately $2.04 \mathrm{~g}$ of monobasic potassium phosphate in $800 \mathrm{~mL}$ of HPLC-grade water, adjusting the $\mathrm{pH}$ to $5.20 \pm 0.05$ with potassium hydroxide solution, diluting to $1000 \mathrm{~mL}$ with HPLC-grade water, and filtering through $0.45 \mu \mathrm{m}$ membrane filter. Mobile phase B contained a mixture of $\mathrm{pH} 5.2$ phosphate buffer and acetonitrile in the ratio of $70: 30(\mathrm{v} / \mathrm{v})$, respectively. For the preparation of diluent, weigh accurately $2.04 \mathrm{~g}$ of monobasic potassium phosphate in $800 \mathrm{~mL}$ of HPLC-grade water, adjust the $\mathrm{pH}$ to $5.70 \pm 0.05$ with potassium hydroxide solution, and dilute to $1000 \mathrm{~mL}$ with HPLC-grade water, and filter through $0.45 \mu \mathrm{m}$ membrane filter and degas for about 10 minutes. Dissolve about $0.9 \mathrm{~g}$ of sodium chloride in $100 \mathrm{~mL}$ of water. This is used as a saline solution. The flow rate of the mobile phase was $0.8 \mathrm{~mL} / \mathrm{min}$. The HPLC gradient program $(\mathrm{T} / \% \mathrm{~B})$ was set as $0.01 / 0,15.0 / 0,20.0 / 7,27.0 / 7,45.0 / 40,55.0 / 75,60.0 / 100$, $70.0 / 100,71.0 / 0$, and $80.0 / 0$. The column temperature was maintained at $30^{\circ} \mathrm{C}$, and detection was monitored at a wavelength of $210 \mathrm{~nm}$. The injection volume was $20 \mu \mathrm{L}$.

2.3. Preparation of Stock Solutions. For the preparation of standard solution, weigh accurately and transfer about $66 \mathrm{mg}$ doripenem monohydrate working standard into a $25 \mathrm{~mL}$ volumetric flask, add about $15 \mathrm{~mL}$ of diluent, sonicate to dissolve the material completely, dilute to volume with diluent, and mix well. Pipette $5 \mathrm{~mL}$ of the above stock solution into a $50 \mathrm{~mL}$ volumetric flask, dilute to volume with diluent, and mix well. Pipette $5 \mathrm{~mL}$ of the above solution, transfer into a $100 \mathrm{~mL}$ volumetric flask, dilute to volume with diluent, and mix well. Filter about $2 \mathrm{~mL}$ through $0.45 \mu \mathrm{m}$ membrane filter and for the preparation of blank solution, dilute $5 \mathrm{~mL}$ of saline solution to $10 \mathrm{~mL}$ with diluent, and mix. The final concentration of standard solution is about $12.5 \mu \mathrm{g} / \mathrm{mL}$.

\subsection{Preparation of Sample Solution}

2.4.1. For $250 \mathrm{mg}$ Vials (for Intravenous Infusion Use). Withdraw the entire content (suspension) of the vial using a syringe with a 21-gauge needle and transfer into a $50 \mathrm{~mL}$ volumetric flask, dilute to volume with saline solution, and mix well. Pipette $5 \mathrm{~mL}$ of the above solution into a $10 \mathrm{~mL}$ volumetric flask, dilute to volume with diluent, and mix well. Further dilutions were carried out to get the final concentration of sample of about $12.5 \mu \mathrm{g} / \mathrm{mL}$. Filter about $2 \mathrm{~mL}$ through $0.45 \mu \mathrm{m}$ or less membrane filter.

2.4.2. For $500 \mathrm{mg}$ Vials (for Intravenous Infusion Use). Withdraw the entire content (suspension) of the vial using a syringe with a 21-gauge needle and transfer into a $100 \mathrm{~mL}$ volumetric flask, dilute to volume with saline solution, and mix well. Pipette $5 \mathrm{~mL}$ of the above solution into a $10 \mathrm{~mL}$ volumetric flask, dilute to volume with diluent, and mix well. Further dilutions were carried out to get the final concentration of sample of about $12.5 \mu \mathrm{g} / \mathrm{mL}$. Filter about $2 \mathrm{~mL}$ through $0.45 \mu \mathrm{m}$ or less membrane filter. Inject $20 \mu \mathrm{L}$ portion of blank, standard solution and test preparation into chromatographic system, record the chromatograms, and measure the response for the peaks.

\section{Results and Discussion}

3.1. Method Development and Optimization. As the published literature and knowledge of the molecule suggest, reversed phase liquid chromatography (RP-HPLC) is suitable for analysis of doripenem. In case of RP-HPLC, various columns are available, but as the main aim of the method was to resolve the compound from degraded products and impurities if any, Hypersil BDS C18, $150 \times 4.6 \mathrm{~mm}, 5 \mu \mathrm{m}$ particles were preferred over the other columns. As per the value of $\mathrm{pk}_{a}$ and solubility of compound, various compositions of mobile phase were tried. Doripenem and degraded products could not be separated without $\mathrm{pH}$ adjustment of the mobile phase. Various $\mathrm{pH}$ ranges (4 to 6) for mobile phase were tried, and the best resolution was obtained with $\mathrm{pH}$ 5.2. 


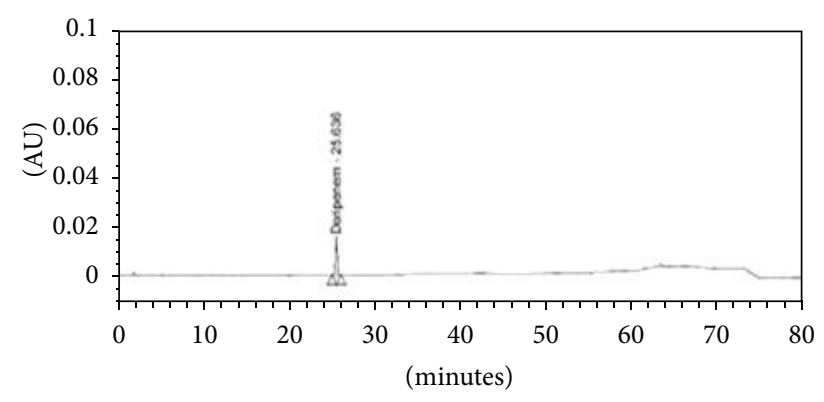

(a)

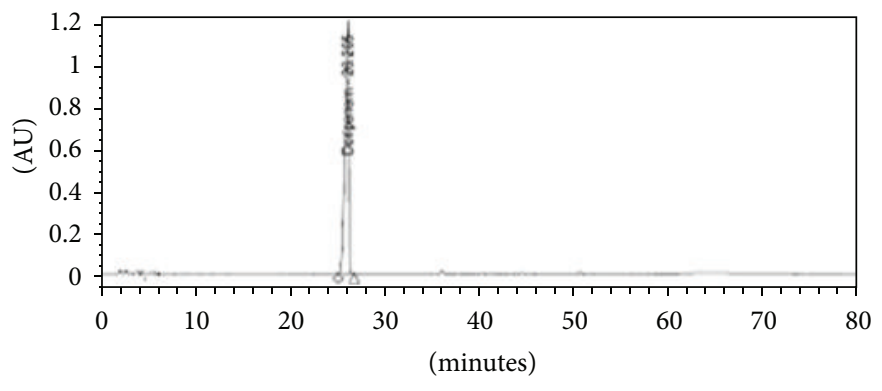

(b)

Figure 2: (a) Typical chromatogram of standard doripenem $(12.5 \mu \mathrm{g} / \mathrm{mL})$ showing retention time at 25.636 min. (b) Standard chromatogram of doripenem at $1 \mathrm{mg} / \mathrm{mL}$ standard solution showing retention time at $26.205 \mathrm{~min}$.

TABLE 1: System precision data of doripenem.

\begin{tabular}{lc}
\hline S. no. & Doripenem standard area \\
\hline 1 & 197222 \\
2 & 196465 \\
3 & 196353 \\
4 & 196067 \\
5 & 195821 \\
6 & 195749 \\
7 & 195153 \\
8 & 194990 \\
9 & 194928 \\
10 & 194662 \\
Average & 195741 \\
\% RSD & 0.4 \\
\hline
\end{tabular}

The chromatographic conditions were optimized with a view to develop a stability indicating assay method, which can separate the drug from its degraded products with good resolution. Mobile phase consisting of acetonitrile, methanol, and $\mathrm{pH} 5.2$ phosphate buffer, at a flow rate of $0.8 \mathrm{~mL} / \mathrm{min}$, was found to be satisfactory to obtain well-resolved peaks with better reproducibility and repeatability for doripenem.

\subsection{Method Validation}

3.2.1. System Suitability and System Precision. The standard solution, prepared by using doripenem monohydrate working standard as per test method, was injected 10 times into the HPLC system. The \% RSD for areas of ten replicate injections was found to be 0.4 (Figure 2(a) and Table 1). Doripenem standard solution containing $1 \mathrm{mg} / \mathrm{mL}$ concentration was also prepared and injected into the HPLC system, and the \% RSD was calculated (Figure 2(b)). The found \% RSD was within the limit of NMT 5\%. The system suitability parameters were also evaluated and found to be 0.9 (acceptance criteria NMT $2.0 \%$ ), and USP plate count was found to be 53021 (acceptance criteria NLT 12000), respectively.

3.2.2. Specificity. Specificity is the ability of the method to measure the analyte response in the presence of its potential impurities [16]. A study was conducted to demonstrate the effective separation of degradants. Separate portions of samples were exposed to following stress conditions to induce degradation. Stress studies were performed at a concentration of $1000 \mu \mathrm{g} / \mathrm{mL}$. Intentional degradation was attempted by the stress conditions of acid and base in which drug product was separately stressed with $0.1 \mathrm{~N} \mathrm{HCl}$ and $0.1 \mathrm{~N} \mathrm{NaOH}$ on bench top for 30 and 10 minutes, respectively. For oxidative degradation the drug was stressed with $1 \% \mathrm{H}_{2} \mathrm{O}_{2}$ in water bath at $40^{\circ} \mathrm{C}$ for 20 minutes. In case of heat degradation, the drug was exposed to dry heat at $105^{\circ} \mathrm{C}$ for 24 hours. Humidity stress was carried out by exposing the drug with $25^{\circ} \mathrm{C}, 90 \% \mathrm{RH}$ for about 279 hours and 30 minutes. For water degradation, the drug product was stressed with water in water bath at $70^{\circ} \mathrm{C}$ for 30 minutes, and photolytic degradation was carried out by exposing the drug with visible light for 280 hours and to UV light for 95 hours. Stressed samples were injected into the HPLC system equipped with photodiode array detector as per test method conditions. All degradants peaks were resolved from doripenem peak in the chromatograms of all stressed samples. The chromatograms of the stressed samples were evaluated for peak purity of doripenem using Waters Empower software. For all forced degradation samples, the peak purity of doripenem was passed as purity angle is less than the purity threshold with no purity flag. Thus, this method is considered to be stability indicating. Among all the stress conditions the drug was stable under photolytic degradation (Table 2). Typical chromatogram of unstressed sample and all the stress conditioned samples along with the purity plot are shown in (Figure 3).

3.2.3. Linearity of Detector Response. Linearity of detector response was established by plotting a graph of concentration versus area of doripenem and determining the correlation coefficient. A series of solutions of doripenem standard was prepared in the concentration range of 0.335 to $76.129 \mu \mathrm{g} / \mathrm{mL}$. A graph was plotted to concentration in $\mu \mathrm{g} / \mathrm{mL}$ on the abscissa versus response on the ordinate. The detector response was found to be linear with a correlation coefficient of 0.999 . 


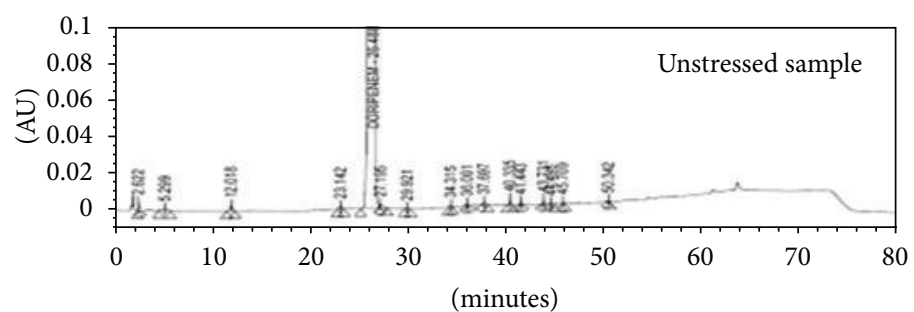

(a)

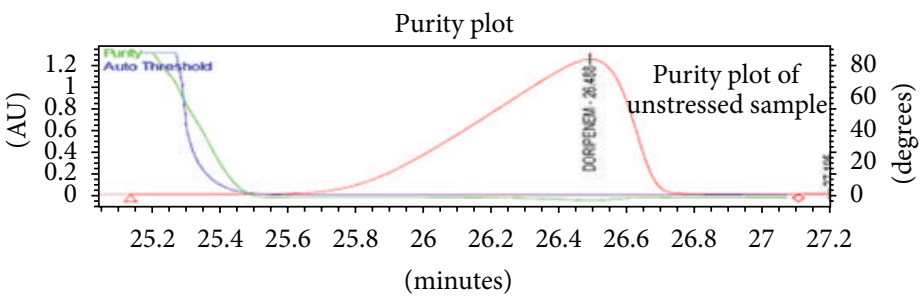

PA: 1.179 TH: 3.143

— Purity

— Peak: doripenem

_ Autothreshold

(b)

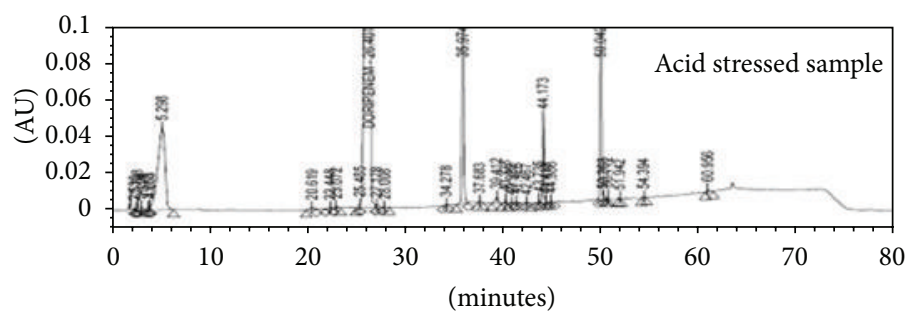

(c)

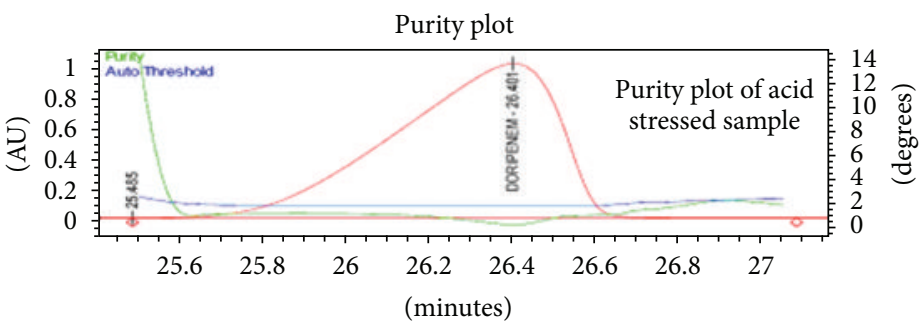

PA: 0.549 TH: 1.638

- Purity

Peak: doripenem

Autothreshold

(d)

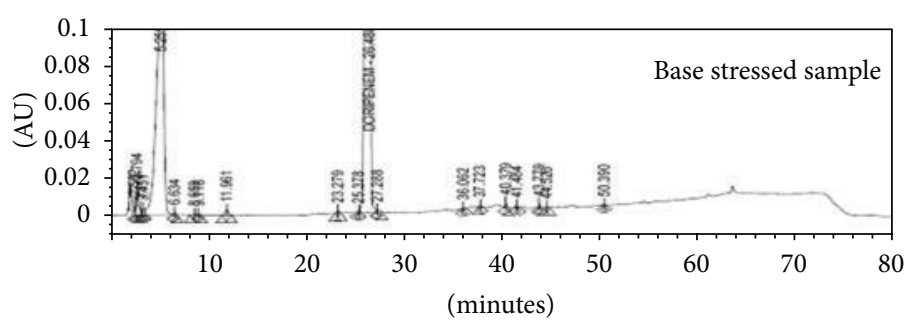

(e)

Figure 3: Continued. 


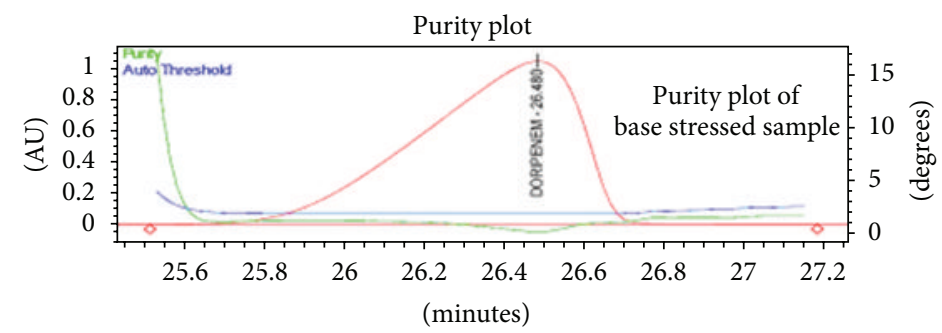

$\begin{array}{ll}\text { PA: } 0.604 \text { TH: } 1.71 & - \text { Purity } \\ \text { Peak: doripenem } & \quad \text { Autothreshold }\end{array}$

(f)

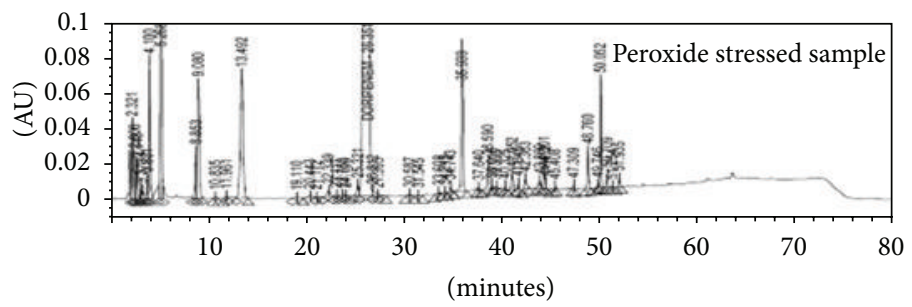

(g)

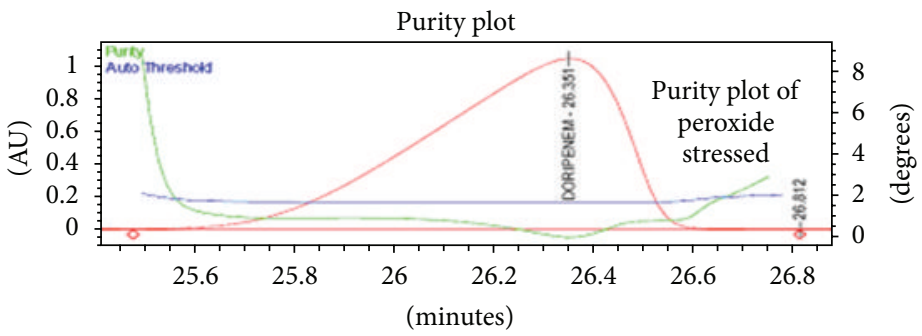

PA: 0.566 TH: 1.706

- Purity

- Peak: doripenem

_ Autothreshold

(h)

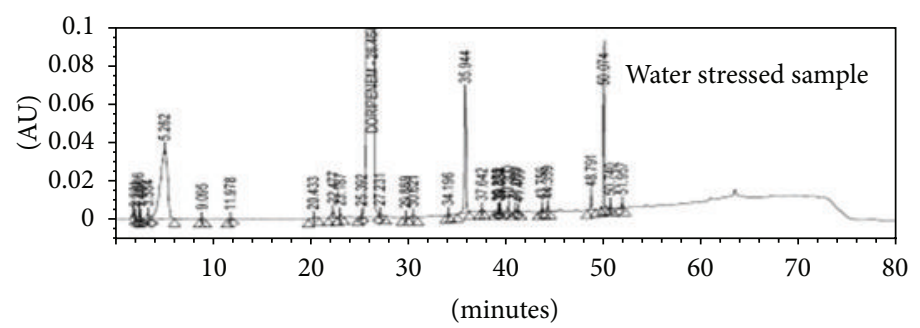

(i)

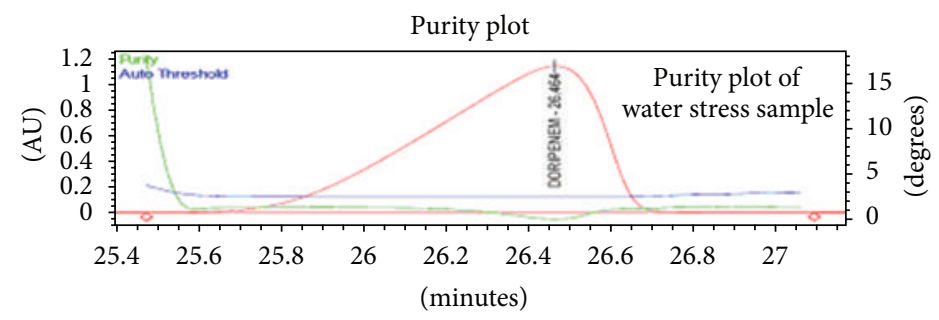

PA: 0.783 TH: 2.461

— Purity

— Peak: doripenem

_ Autothreshold

(j)

Figure 3: Continued. 


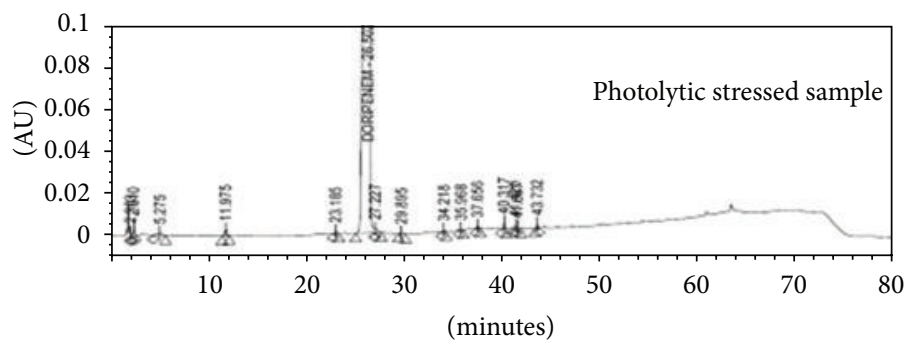

(k)

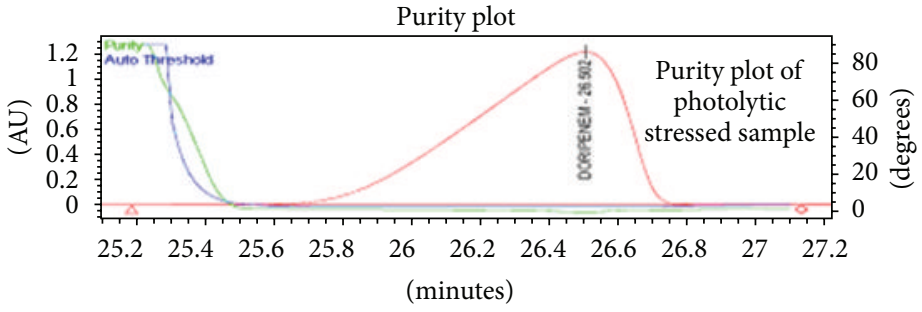
PA: $0.841 \mathrm{TH}: 3.165$
- Purity
_ Peak: doripenem
— Autothreshold

(1)

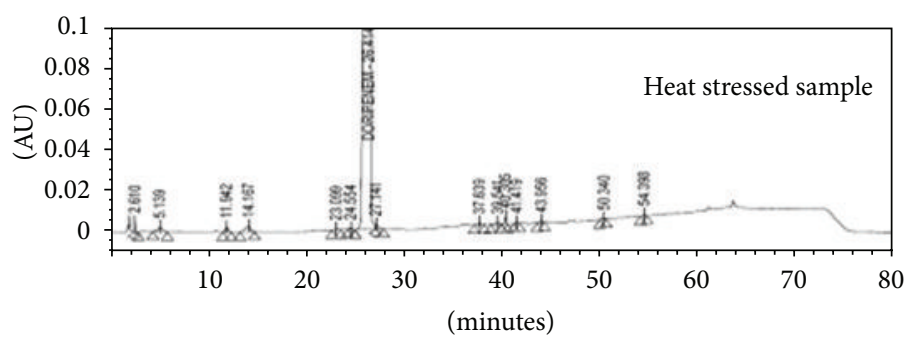

(m)

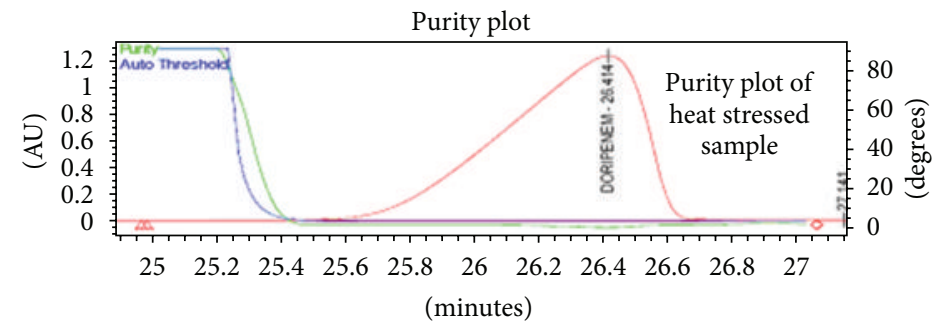

PA: 0.874 TH: 3.224

— Peak: doripenem

- Purity

_ Autothreshold

(n)

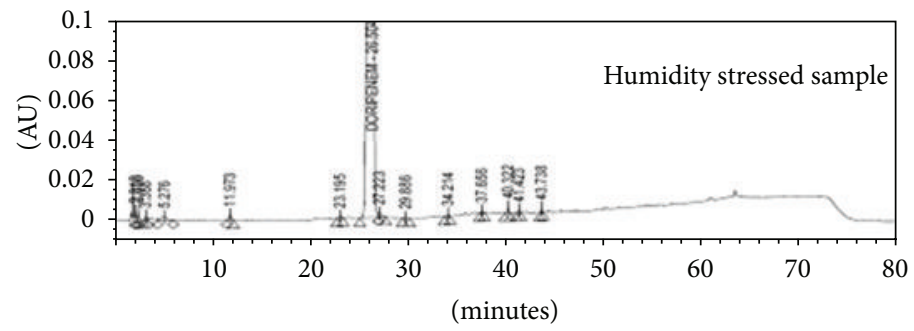

(o)

Figure 3: Continued. 


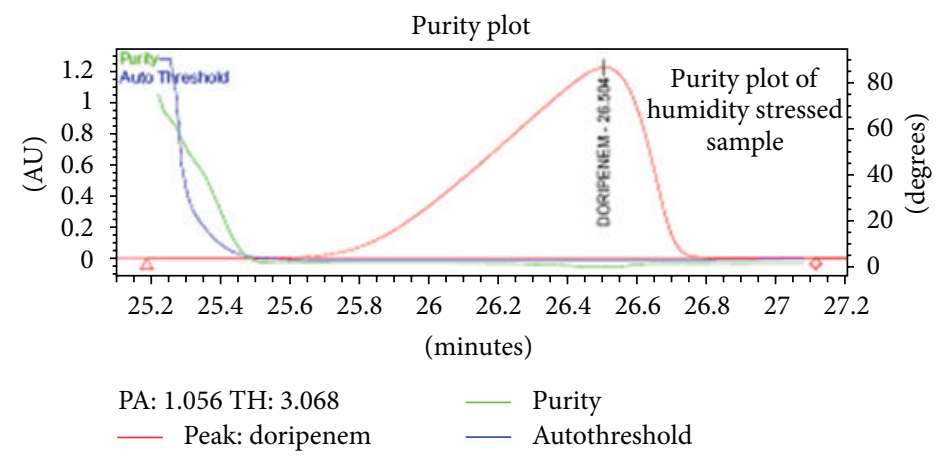

(p)

FIGURE 3: Typical chromatogram of various stressed samples and purity plot of doripenem.

TABLE 2: Peak purity results of forced degradation studies of drug product.

\begin{tabular}{lcccc}
\hline Stress condition & \% Degradation & Purity angle & Purity threshold & Purity flag \\
\hline Acid stress & 24.0 & 0.549 & 1.638 & No \\
Base stress & 18.3 & 0.604 & 1.710 & No \\
Oxidation stress & 23.1 & 0.566 & 1.706 & No \\
Water stress & 9.7 & 0.783 & 2.461 & No \\
Photolytic stress & 0.0 & 0.841 & 3.165 & No \\
Heat stress & 0.3 & 0.874 & 3.224 & No \\
Humidity stress & 0.2 & 1.066 & 3.068 & No \\
\hline
\end{tabular}

3.2.4. Limit of Detection and Limit of Quantitation. A study to establish the limit of detection (LOD) and limit of quantitation (LOQ) of doripenem was conducted. LOD and LOQ were determined by the calibration plot method. A specific calibration plot was constructed using samples containing amount of analyte in the range of LOD and LOQ. The LOD and LOQ for doripenem were found to be 0.109 and $0.331 \mu \mathrm{g} / \mathrm{mL}$, respectively. LOD and LOQ were calculated by use of the equations:

$$
\begin{aligned}
& \mathrm{LOD}=\mathrm{Cd} \times \frac{\text { Syx }}{b}, \\
& \mathrm{LOQ}=\mathrm{Cq} \times \frac{\text { Syx }}{b},
\end{aligned}
$$

where Cd and Cq are the coefficients for LOD and LOQ, Syx is the residual variance of the regression, and $b$ is the slope. Calculations were performed by using values of $\mathrm{Cd}$ and $\mathrm{Cq}$ of 3.3 and 10. Precision at the limit of quantitation and detection was checked by the analyzing of six test solutions prepared at these levels. Peak area RSD was 1.5\% and 3.85\% for LOQ and LOD solutions, respectively.

3.2.5. Precision. Precision was considered at two levels of the ICH suggestions-repeatability and intermediate precision. The repeatability of sample application was determined as intraday variation, whereas intermediate precision was determined by measuring interday variation of the analysis of doripenem six times. The assay results for repeatability (intraday) and intermediate precision (interday) were $99.55 \%$ and $99.96 \%$, respectively.
3.2.6. Accuracy. The accuracy was evaluated by the recovery studies, which were carried out by spiking five known amounts of doripenem in placebo suspension (range from 50-150\% label claim). Three samples were prepared at each concentration. The average recovery at each level was within $100 \pm 2 \%$, and RSD at each level was $\leq 1 \%$.

3.2.7. Bench Top and Refrigerator Stability of Solutions. A study to establish stability of standard solution on bench top was conducted over a period of one day. The standard solution prepared as per test procedure was injected at initial and 1 day against freshly prepared standard each time. From the results, it was observed that the standard solution was not stable on bench top even for one day (Table 3). A study to establish stability of standard solution in refrigerator was conducted over a period of 2 days. The standard solution prepared as per test procedure was injected at initial, 1 day, and 2 days against freshly prepared standard each time. From the results, it was observed that the standard solution is stable for 2 days in refrigerator (Table 4). A study to establish stability of mobile phase on bench top was conducted over a period of about 3 days. Mobile phase was prepared as per the test procedure and kept at bench top in well-closed container. Standard solutions were prepared as per the test method and injected with the mobile phase kept on bench top at initial, one day, and third day. System suitability parameters were evaluated, and the results were found to be within the acceptance criteria (USP plate count, tailing factor, and the ratio for the peak areas of doripenem from five replicate injections of standard solutions were 44938, 0.9, and $1 \%$ 
TABLE 3: Bench top stability of standard solution of doripenem.

\begin{tabular}{|c|c|c|c|c|c|c|}
\hline \multicolumn{7}{|c|}{ Stability of standard } \\
\hline \multicolumn{2}{|c|}{ Initial } & \multicolumn{2}{|c|}{1 day } & \multicolumn{2}{|c|}{2 day } & \multirow{2}{*}{$\begin{array}{l}\text { Acceptance criteria } \\
\text { Difference in \% assay } \\
\text { for standard }\end{array}$} \\
\hline \% Assay & $\%$ Diff & $\%$ Assay & $\%$ Diff & $\%$ Assay & $\%$ Diff & \\
\hline $95.3^{*}$ & NA & 91.0 & 4.3 & NA & NA & $\begin{array}{l}\text { Solution with respect } \\
\text { to initial shall be } \pm 3.0\end{array}$ \\
\hline
\end{tabular}

* Potency of working standard as doripenem.

NA: not applicable.

TABLE 4: Refrigerator stability of standard solution of doripenem.

\begin{tabular}{|c|c|c|c|c|c|c|}
\hline \multicolumn{7}{|c|}{ Stability of standard } \\
\hline \multicolumn{2}{|c|}{ Initial } & \multicolumn{2}{|c|}{1 day } & \multicolumn{2}{|c|}{2 day } & Acceptance criteria \\
\hline$\%$ Assay & $\%$ Diff & \% Assay & \% Diff & $\%$ Assay & \% Diff & $\begin{array}{l}\text { Difference in \% assay } \\
\text { for standard }\end{array}$ \\
\hline $95.3^{*}$ & NA & 97.0 & 1.7 & 93.4 & 1.9 & $\begin{array}{l}\text { solution with respect } \\
\text { to initial shall be } \pm 3.0\end{array}$ \\
\hline
\end{tabular}

* Potency of working standard as doripenem.

NA: not applicable.

resp.), From the above study, it was established that the mobile phase is stable for a period of 3 days on bench top.

\subsubsection{Robustness}

(1) Effect of Variation in Mobile Phase A Composition (Acetonitrile). A study was conducted to determine the effect of variation in mobile phase composition A (acetonitrile). Acetonitrile composition was varied from $90 \%$ to $110 \%$ to the specified method composition and evaluated robustness. Standard solution and test solution were prepared as per test method, and the solutions were injected in the HPLC system at $90 \%, 100 \%$, and at $110 \%$ compositions of acetonitrile. The system suitability parameters like tailing factor, USP plate count, and the ratio for the peak area of doripenem from five replicate injections of standard solutions were evaluated for the $90 \%, 100 \%$, and $110 \%$ compositions of acetonitrile. It was observed that system suitability parameters were comparable with those obtained from test method specified acetonitrile composition. From the above study, it was established that the allowable variation in acetonitrile composition is from $90 \%$ to $110 \%$.

(2) Effect of Variation in Mobile Phase A Composition (Methanol). A study was conducted to determine the effect of variation in mobile phase A composition (methanol). Methanol composition was varied from $90 \%$ to $110 \%$ to the specified method composition and evaluated robustness. Standard solution and test solution were prepared as per test method, and the solutions were injected in the HPLC system at $90 \%, 100 \%$, and at $110 \%$ compositions of methanol. The system suitability parameters like tailing factor, USP plate count, and the ratio for the peak area of doripenem from five replicate injections of standard solutions were evaluated for the $90 \%, 100 \%$, and $110 \%$ compositions of methanol. It was observed that system suitability parameters were comparable with those obtained from test method specified methanol composition. From the above study, it was established that the allowable variation in methanol composition is from $90 \%$ to $110 \%$.

(3) Effect of Variation in Mobile Phase B Composition (Acetonitrile). A study was conducted to determine the effect of variation in mobile phase B composition (acetonitrile). Acetonitrile composition was varied from $90 \%$ to $110 \%$ to the specified method composition and evaluated robustness. Standard solution and test solution were prepared as per test method, and the solutions were injected in the HPLC system at $90 \%, 100 \%$ and at $110 \%$ compositions of acetonitrile. The system suitability parameters like tailing factor, USP plate count and the ratio for the peak area of doripenem from five replicate injections of standard solutions were evaluated for the $90 \%, 100 \%$, and $110 \%$ compositions of acetonitrile. It was observed that system suitability parameters were comparable with those obtained from test method specified acetonitrile composition. From the above study, it was established that the allowable variation in acetonitrile composition is from $90 \%$ to $110 \%$.

(4) Effect of Variation in Column Temperature. A study was conducted to determine the effect of variation in column temperature. Column temperature varied at $25^{\circ} \mathrm{C}$ and $35^{\circ} \mathrm{C}$ and evaluated robustness. Standard solution and test solution were prepared as per test method, and the solutions were injected in the HPLC system as per the test method at $25^{\circ} \mathrm{C}$ and $35^{\circ} \mathrm{C}$. The system suitability parameters were evaluated for the column temperatures at $25^{\circ} \mathrm{C}$ and $35^{\circ} \mathrm{C}$. It was observed that system suitability was comparable with those obtained from test method specified column temperature $\left(30^{\circ} \mathrm{C}\right)$. From the above study, it was established that the 
allowable variation in column temperature is from $25^{\circ} \mathrm{C}$ to $35^{\circ} \mathrm{C}$.

(5) Effect of Variation in pH of Buffer in Mobile Phase. A study was conducted to determine the effect of variation in $\mathrm{pH}$ of buffer in mobile phase; $\mathrm{pH}$ of buffer varied from $\mathrm{pH} 5.0$ to pH 5.4 and evaluated robustness. Standard solution and test solution were prepared as per test method, and the solutions were injected in the HPLC system as per the test method with buffers of $\mathrm{pH} 5.0, \mathrm{pH} 5.2$, and $\mathrm{pH}$ 5.4. The system suitability parameters were evaluated for the $\mathrm{pH}$ of buffer in mobile from pH 5.0 and pH 5.4. It was observed that system suitability were comparable for buffer with $\mathrm{pH} 5.0$ and 5.4 with those obtained from test method specified $\mathrm{pH}$. From the above study, it was established that the allowable variation in $\mathrm{pH}$ of buffer is from 5.0 to $\mathrm{pH} 5.4$.

(6) Effect of Variation in Flow Rate. A study was conducted to determine the effect of variation in flow rate. Flow rate varied from $0.6 \mathrm{~mL} / \mathrm{min}$ to $1.0 \mathrm{~mL} / \mathrm{min}$ and evaluated robustness. Standard solution and test solution were prepared as per test method, and the solutions were injected in the HPLC system with flow rate which varied from $0.6 \mathrm{~mL} / \mathrm{min}$ to $1.0 \mathrm{~mL} / \mathrm{min}$. The system suitability parameters were evaluated for the flow rate which varied from $0.6 \mathrm{~mL} / \mathrm{min}$ to $1.0 \mathrm{~mL} / \mathrm{min}$. It was observed that system suitability was comparable for the flow rate of $0.6 \mathrm{~mL} / \mathrm{min}$ and to $1.0 \mathrm{~mL} / \mathrm{min}$ with those obtained from test method specified flow rate. From the above study, it was established that allowable variation in flow rate is from $0.6 \mathrm{~mL} / \mathrm{min}$ to $1.0 \mathrm{~mL} / \mathrm{min}$.

\section{Conclusion}

A gradient stability-indicating reversed phase high performance liquid chromatographic method for doripenem for injection was undertaken in the present research work. The method is found to be specific, as there was no interference of any coeluting impurities after stress degradation study. The degraded products are well resolved with satisfactory peak purity index, indicating that the method can also be useful for determination of degraded products. The proposed method is found to be accurate, precise, sensitive, and robust. Hence, it can be used successfully for the routine analysis of doripenem in injection and for analysis of stability samples obtained during accelerated stability study.

\section{References}

[1] R. N. Jones, H. S. Sader, and T. R. Fritsche, "Comparative activity of doripenem and three other carbapenems tested against Gram-negative bacilli with various $\beta$-lactamase resistance mechanisms," Diagnostic Microbiology and Infectious Disease, vol. 52, no. 1, pp. 71-74, 2005.

[2] H. M. Wexler, A. E. Engel, D. Glass, and C. Li, "In vitro activities of doripenem and comparator agents against 364 anaerobic clinical isolates," Antimicrobial Agents and Chemotherapy, vol. 49, no. 10, pp. 4413-4417, 2005.

[3] R. N. Jones, H. K. Huynh, and D. J. Biedenbach, "Activities of doripenem (S-4661) against drug-resistant clinical pathogens,"
Antimicrobial Agents and Chemotherapy, vol. 48, no. 8, pp. 31363140, 2004.

[4] P. A. Psathas, A. Kuzmission, K. Ikeda, and S. Yasuo, "Stability of doripenem in vitro in representative infusion solutions and infusion bags," Clinical Therapeutics, vol. 30, no. 11, pp. 20752087, 2008.

[5] C. Sutherland and D. P. Nicolau, "Development of an HPLC method for the determination of doripenem in human and mouse serum," Journal of Chromatography B, vol. 853, no. 1-2, pp. 123-126, 2007.

[6] J. Cielecka-Piontek, A. Jelińska, A. Dołhań, and P. Zalewski, "Kinetic and thermodynamic analysis of degradation of doripenem in the solid state," International Journal of Chemical Kinetics, vol. 44, pp. 722-728, 2012.

[7] L. Mantovani, C. T. M. Sayago, V. B. Camargo et al., "Stabilityindicating RP-HPLC method for analysis of the antibiotic doripenem in pharmaceutical formulation-comparison to UV spectrophotometry and microbiological assay," Acta Chromatographica, vol. 24, pp. 367-382, 2012.

[8] J. Cielecka-Piontek and A. Jelinska, "The UV-Derivative spectrophotometry for the determination of doripenem in the presence of its degradation products," Spectrochimica Acta A, vol. 77, pp. 554-557, 2010.

[9] J. Cielecka-Piontek, K. Michalska, P. Zalewski, and A. Jelińska, "Recent advances in stability studies of carbapenems," Current Pharmaceutical Analysis, vol. 7, pp. 213-227, 2011.

[10] E. Dailly, R. Bouquié, G. Deslandes, P. Jolliet, and R. le Floch, "A liquid chromatography assay for a quantification of doripenem, ertapenem, imipenem, meropenem concentrations in human plasma: application to a clinical pharmacokinetic study," Journal of Chromatography B, vol. 879, no. 15-16, pp. 1137-1142, 2011.

[11] K. Michalska, G. Pajchel, and S. Tyski, "Determination of doripenem and related substances in medicinal product using capillary electrophoresis," Journal of Separation Science, vol. 34, no. 4, pp. 475-482, 2011.

[12] J. L. Crandon, C. Sutherland, and D. P. Nicolau, "Stability of doripenem in polyvinyl chloride bags and elastomeric pumps," American Journal of Health-System Pharmacy, vol. 67, no. 18, pp. 1539-1544, 2010.

[13] K. Berthoin, C. S. le Duff, J. Marchand-Brynaert, S. Carryn, and P. M. Tulkens, "Stability of meropenem and doripenem solutions for administration by continuous infusion," Journal of Antimicrobial Chemotherapy, vol. 65, no. 5, pp. 1073-1075, 2010.

[14] ICH Q1A (R2), "Stability Testing of New Drug Substances and Products," 2003.

[15] ICH Q2 (R1), "Validation of Analytical Procedures: Text and Methodology," 2005.

[16] "Stability testing of new drug substance and products Q1A (R2)," in Proceedings of the International Conference on Harmonization (ICH) of Technical Requirements for the Registration of Pharmaceuticals for Human Use, pp. 1-18, February 2003. 

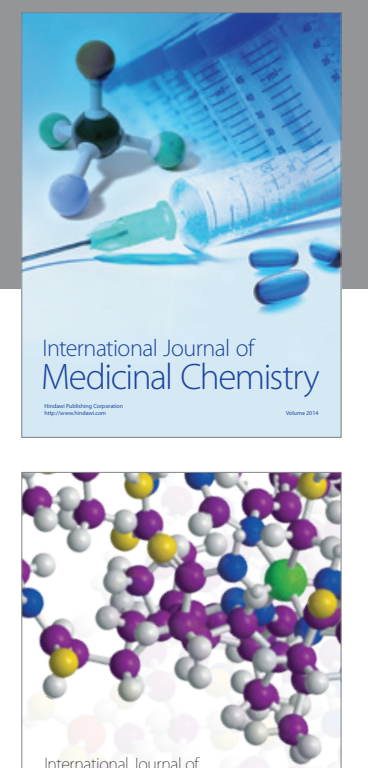

\section{Carbohydrate} Chemistry

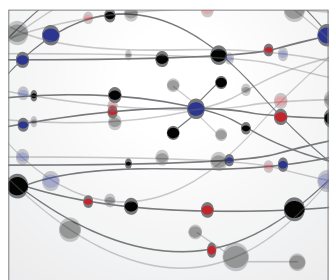

The Scientific World Journal
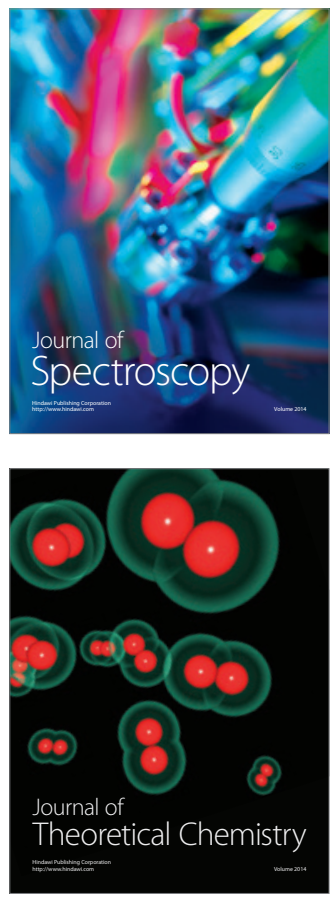
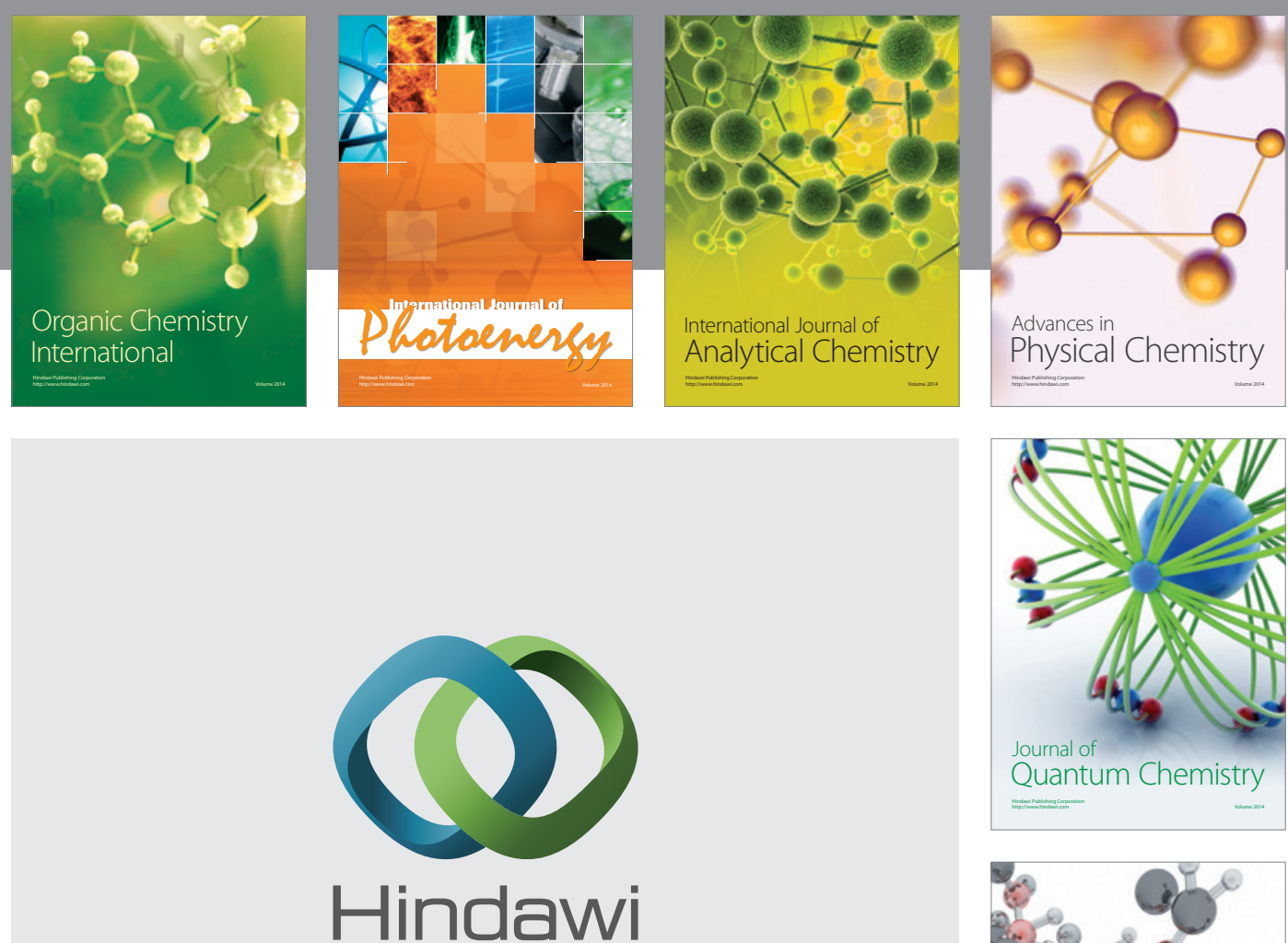

Submit your manuscripts at

http://www.hindawi.com

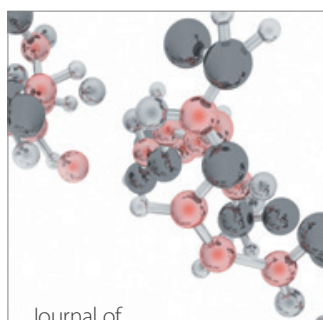

Analytical Methods

in Chemistry

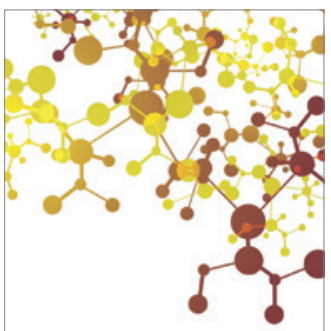

Journal of

Applied Chemistry

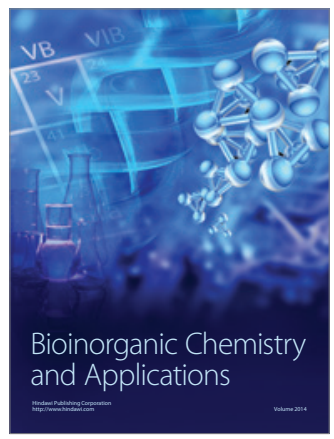

Inorganic Chemistry
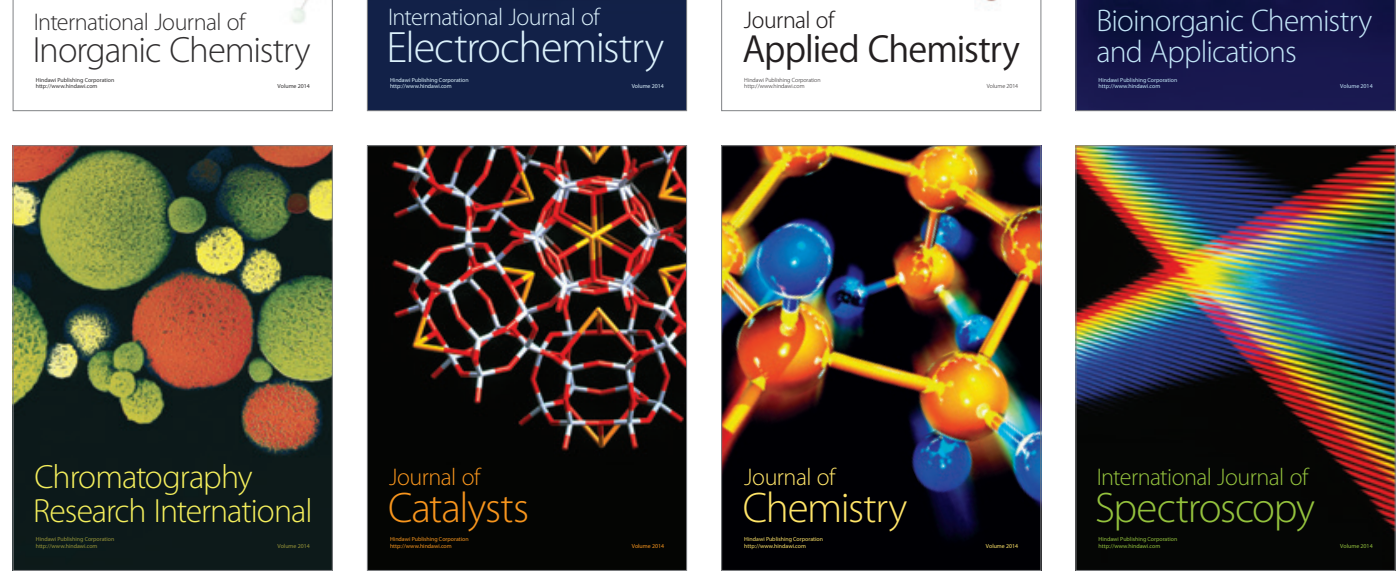